\title{
DISCURSOS DE ÓDIO EM REDES SOCIAIS: JURISPRUDÊNCIA BRASILEIRA
}

\author{
Rosane Leal da Silva, Andressa Nichel, Anna Clara Lehmann Martins \\ e Carlise Kolbe Borchardt \\ HATE SPEECH IN SOCIAL NETWORKS: BRAZILIAN CASE LAW
}

\section{RESUMO}

TENDO-SE EM VISTA A CRESCENTE POPULARIZAÇĀO DE REDES DE RELACIONAMENTO VIRTUAL COMO O ORKUT, A FACILIDADE DE DIVULGAÇÃO DE CONTEÚdOS PREJUDICIAIS NESSES MEIOS, E A NECESSIDADE DE O DIREITO ADAPTAR-SE ÀS DEMANDAS DA ERA DA INFORMAC̣ÃO, O PRESENTE ARTIGO BUSCA ELUCIDAR SE E COMO O SISTEMA JUDICIÁRIO BRASILEIRO JULGA LITÍGIOS ENVOLVENDO DISCURSOS DE ÓDIO PUBLICADOS EM REDES SOCIAIS. DE FORMA A CUMPRIR ESSE OBJETIVO, UTILIZOU-SE DE ABORDAGEM QUANTITATIVA (COLETA SISTEMÁTICA DE DADOS JURISPRUDENCIAIS NOS SítIOS DE TRIBUNAIS, TENDO POR FILTRO A PALAVRa "ORKUT") E QUALITATIVA (ANÁLISE DAS JURISPRUDÊNCIAS PERTINENTES). COMO CONCLUSÃO, VERIFICOU-SE QUE O PODER JUdicIÁRIO dO BRASIL, EMBORA RECEBA POUCAS DEMANDAS SOBRE DISCURSOS INTOLERANTES VEICULADOS EM REDE VIRTUAL, POSICIONA-SE DE FORMA A PRIVILEGIAR A DIGNIDADE DAS PESSOAS QUE INTERAGEM NO CIBERESPAÇO.

\section{PALAVRAS-CHAVE}

DISCURSO DE ÓDIO; DIREITOS FUNDAMENTAIS; SISTEMA JUDICIÁRIO BRASILEIRO; REDES SOCIAIS; INTERNET.

\section{ABSTRACT}

CONSIDERING THE GROWING POPULARIZATION OF VIRTUAL SOCIAL NETWORKS LIKE ORKUT, THE EASINESS TO SPREAD HARMFUL CONTENT IN THIS MEDIA, AND THE NEED OF LAW TO ADAPT ITSELF TO THE DEMANDS OF THE "INFORMATION AGE", THE PRESENT PAPER AIMS TO ELUCIDATE WHETHER AND HOW THE BRAZILIAN JUDICIAL SYSTEM JUDGES CASES INVOLVING HATE SPEECH PUBLISHED IN SOCIAL NETWORKS. IN ORDER TO FULFILL THIS OBJECTIVE, TWO APPROACHES HAVE BEEN USED: ONE QUANTITATIVE (SYSTEMIC GATHERING OF JURISPRUDENTIAL DATA IN THE TRIBUNALS'SITES, HAVING FOR FILTER THE WORD "ORKUT") AND THE OTHER, QUALITATIVE (ANALYSIS OF RELEVANT CASE LAW). IN CONCLUSION, IT WAS VERIFIED THAT THE JUDICIARY IN BRAZIL, ALTHOUGH IT RECEIVES FEW COMPLAINTS ABOUT INTOLERANT DISCOURSES CONVEYED IN VIRTUAL NETWORK, IT IS POSITIONED SO AS TO PRIVILEGE THE DIGNITY OF PEOPLE INTERACTING IN CYBERSPACE.

\section{KEYWORDS}

HATE SPEECH; CONSTITUTIONAL RIGHTS; BRAZILIAN JUDICIAL SYSTEM; SOCIAL NETWORKS; INTERNET.

\section{INTRODUÇÃO}

A internet revolucionou as maneiras de o ser humano se comunicar. Essa inovadora tecnologia da informação, cujo diferencial é a extrema rapidez e a vasta amplitude de suas operações, permite ao homem externar seus pensamentos, suas opiniões, suas escolhas, externar a si próprio das mais variadas formas e a um largo espectro de outros homens que, como ele, também se projetam no ciberespaço. Dadas as 
múltiplas possibilidades de compartilhamento informacional entre diferentes pessoas, oriundas de diferentes culturas e conhecedoras de diferentes áreas do saber, muito se fala sobre a formação de uma inteligência coletiva na rede. Entretanto, se o mundo virtual serve como mecanismo privilegiado de projeção do ser humano, tal qual um espelho, ele também virtualmente reflete os aspectos pouco promissores da realidade palpável.

Através da rede, o homem comete ilícitos, propaga mensagens de conteúdo prejudicial, viola direitos fundamentais dos demais usuários. Essa problematização, que não é essencialmente nova, porém mais complexa e potencializada por uma roupagem tecnológica, exige atitudes adequadas por parte dos entes encarregados da proteção do ser humano em sua dignidade, entre esses, o Estado. Seu papel é de suma importância a fim de que se desfaça o ditame do senso comum de que a internet é um ambiente à margem do Direito. Embora os fluxos informacionais da rede transcendam as fronteiras nacionais, estando em todo e em nenhum lugar concomitantemente (daí uma de suas características principais, a desterritorialização), permanece a incumbência do Estado de intervir quando um indivíduo ou grupo pertencente ao seu território tem seus direitos lesados por conteúdos publicados no ambiente virtual.

Este artigo visa identificar e analisar as respostas dadas pelo Estado brasileiro, em sua função judiciária, aos litígios envolvendo uma categoria específica de conteúdo prejudicial online, o discurso de ódio veiculado em redes sociais. Genericamente, esse discurso se caracteriza por incitar a discriminação contra pessoas que partilham de uma característica identitária comum, como a cor da pele, o gênero, a opção sexual, a nacionalidade, a religião, entre outros atributos. A escolha desse tipo de conteúdo se deve ao amplo alcance desta espécie de discurso, que não se limita a atingir apenas os direitos fundamentais de indivíduos, mas de todo um grupo social, estando esse alcance agora potencializado pelo poder difusor da rede, em especial de redes de relacionamento como Orkut e Facebook. O enfoque nessas plataformas se justifica pelo fato de elas terem se tornado a forma de entretenimento favorita de internautas do Brasil e de outros países, colocando grandes contingentes em mútuo e rápido contato. Apesar do incremento que representam para as relações humanas, essas redes podem revelar-se ferramentas facilitadoras de propagação de mensagens odientas e de incitação de pessoas, sobretudo através das chamadas comunidades virtuais. Tais aspectos, somados à ainda incipiente produção científica brasileira sobre discurso de ódio sob a óptica virtual, justificam que se busque aferir como o Poder Judiciário do Brasil enfrenta a questão.

De forma a cumprir esse objetivo, utilizou-se de duas abordagens: quantitativa e qualitativa. Na abordagem quantitativa, preocupou-se em verificar a existência e a intensidade numérica de decisões judiciais sobre discursos de ódio presentes em uma rede de relacionamento específica e popular no Brasil, o Orkut, em comparação com 
outras causas de pedir relativas ao mesmo sítio. Já na abordagem qualitativa, importou analisar o tratamento conferido a esse discurso nos julgados pertinentes.

A técnica de pesquisa empregada foi documental e compreendeu (1) pesquisa bibliográfica, com a finalidade de estabelecer as categorias conceituais para a definição do discurso de ódio, liberdade de expressão e dignidade da pessoa humana no ordenamento jurídico brasileiro, referências que servirão para etapas posteriores da pesquisa, utilizando como marco teórico as construções de Winfried Brugger, Samantha Ribeiro Meyer-Pflug e Ingo Wolfgang Sarlet; (2) coleta sistemática de dados jurisprudenciais em tribunais recursais da justiça comum - Tribunais de Justiça, Tribunais Regionais Federais (TRFs), Superior Tribunal de Justiça (STJ) e Supremo Tribunal Federal (STF) -, e (3) análise da jurisprudência concernente a esta espécie de discurso.

O presente artigo está estruturado em três partes, correspondentes às etapas da pesquisa efetuada. Primeiramente, far-se-á uma explicação acerca de o que é considerado discurso de ódio e como este se relaciona com a internet e o ordenamento jurídico brasileiro. Após, partir-se-á para a exposição e exame dos dados quantitativos auferidos na pesquisa jurisprudencial e a pormenorização do método de coleta e de sistematização utilizado. Na terceira parte, por meio da análise qualitativa de julgado, responder-se-á à pergunta que constitui o cerne deste artigo: Qual é o tratamento dado pelo Poder Judiciário ao discurso de ódio veiculado em redes sociais?

\section{SOBRE O DISCURSO DE ÓDIO}

O discurso de ódio compõe-se de dois elementos básicos: discriminação e externalidade. É uma manifestação segregacionista, baseada na dicotomia superior (emissor) e inferior (atingido) e, como manifestação que é, passa a existir quando é dada a conhecer por outrem que não o próprio autor. A fim de formar um conceito satisfatório, devem ser aprofundados esses dois aspectos, começando pela externalidade.

A existência do discurso de ódio, assim toda expressão discursiva, exige a transposição de ideias do plano mental (abstrato) para o plano fático (concreto). Discurso não externado é pensamento, emoção, o ódio sem o discurso; e não causa dano algum a quem porventura possa ser seu alvo, já que a ideia permanece na mente de seu autor. Para esse caso, é inconcebível a intervenção jurídica, pois a todos é livre o pensar.

Nas palavras de Jeremy Waldron (2010, p. 1601), o problema se instaura quando o pensamento ultrapassa esses limites dando lugar à duradoura presença da palavra publicada. Nessa situação, o discurso existe, está ao alcance daqueles a quem busca denegrir e daqueles a quem busca incitar contra os denegridos, e está apto para produzir seus efeitos nocivos, quais sejam: as violações a direitos fundamentais, o ataque à dignidade de seres humanos. Em suma, dessa manifestação pública advêm o dano e a necessidade de intervenção de instâncias com poder de controle, dentre elas, o Direito. 
Ademais de puramente manifestar-se, para caracterizar-se como tal, o discurso de ódio deve manifestar discriminação, ou seja, desprezo por pessoas que compartilham de alguma característica que as torna componentes de um grupo. Essas pessoas são referidas como inferiores, ou ainda, parafraseando Waldron, são tidas como indignas da mesma cidadania dos emissores dessa opinião. ${ }^{1}$ Enfatizando esse teor discriminatório, tem-se a definição de Winfried Brugger para este tipo de discurso: "[refere-se a] palavras que tendam a insultar, intimidar ou assediar pessoas em virtude de sua raça, cor, etnicidade, nacionalidade, sexo ou religião, ou que têm a capacidade de instigar a violência, ódio ou discriminação contra tais pessoas" (2007, p. 118).

A definição peca pela aparente restrição das características que podem ser consideradas objeto de discriminação. O homem, dada sua contingência, é capaz de manifestar numerosas características, concretas ou abstratas, passíveis de reconhecimento, diferenciação e, malgrado seu, discriminação. Faz pouco sentido restringir essas características àquelas tidas como mais recorrentes ou mais graves, pois poderse-ia cometer uma injustiça. O efeito denegridor subsiste tanto na discriminação de gênero quanto na de idosos, por exemplo. Apesar dessa limitação, a citação de Brugger é eficiente no sentido de dividir o tal discurso em dois atos: o insulto e a instigação. O primeiro diz respeito diretamente à vítima, consistindo na agressão à dignidade de determinado grupo de pessoas por conta de um traço por elas partilhado. O segundo ato é voltado a possíveis “outros", leitores da manifestação e não identificados como suas vítimas, os quais são chamados a participar desse discurso discriminatório, ampliar seu raio de abrangência, fomentá-lo não só com palavras, mas também com ações.

Quanto a suas estratégias de persuasão, o discurso de ódio aproveita-se de elementos relativos à área de publicidade e propaganda para angariar adeptos, quais sejam, a criação de estereótipos, a substituição de nomes, a seleção exclusiva de fatos favoráveis ao seu ponto de vista, a criação de "inimigos", o apelo à autoridade e a afirmação e repetição, conforme Brown (1971, p. 27-30). Aliado a isso, o discurso procura aumentar sua probabilidade de aceitação por conta do uso de argumentos emocionais e da ausência de contraposição direta e imediata a tais mensagens. Combinadas essas faces, a que insulta e a que instiga, tem-se que este discurso, além de expressar, procura aumentar a discriminação.

No que concerne à violação provocada, embora esse ponto já tenha sido tocado nesta discussão, faz-se necessário esclarecer que o discurso de ódio fere a dignidade da pessoa humana, característica essencial do homem individual e coletivamente considerado.

O conceito de dignidade da pessoa humana adotado neste artigo é o de Ingo Wolfgang Sarlet, que encara a dignidade sob uma perspectiva filosófica, nas dimensões ontológica e intersubjetiva, e jurídica, nas dimensões negativa e positiva. Filosoficamente, para Sarlet, a dignidade é qualidade inerente e distintiva do ser 
humano (dimensão ontológica), que exige reconhecimento e respeito por parte dos demais seres humanos (dimensão intersubjetiva). Do ponto de vista jurídico, Sarlet diz que a dignidade implica limites à ação humana, como forma de proteção contra atos degradantes (dimensão negativa), ao mesmo tempo que deve ser promovida ativamente para garantir uma vida saudável a todos (dimensão positiva). Nas palavras desse autor:

[A] dignidade da pessoa humana [é] a qualidade intrínseca e distintiva reconhecida em cada ser humano que o faz merecedor do mesmo respeito e consideração por parte do Estado e da comunidade, implicando, neste sentido, um complexo de direitos e deveres fundamentais que assegurem a pessoa tanto contra todo e qualquer ato de cunho degradante e desumano, como venham a lhe garantir as condições existenciais mínimas para uma vida saudável, além de propiciar e promover sua participação ativa e corresponsável nos destinos da própria existência e da vida em comunhão com os demais seres humanos, mediante o devido respeito aos demais seres que integram a rede da vida Sarlet (2011, p. 73, grifos do autor).

Quando uma pessoa dirige um discurso de ódio a outra, a dignidade é vulnerada em sua dimensão intersubjetiva, no respeito que cada ser humano deve ao outro. Mas não só isso. No caso do discurso odiento, vai-se além: é atacada a dignidade de todo um grupo social, não apenas a de um indivíduo. Mesmo que este indivíduo tenha sido diretamente atingido, aqueles que compartilham a característica ensejadora da discriminação, ao entrarem em contato com o discurso odiento, compartilham a situação de violação. Produz-se o que se chama de vitimização difusa. Não se afigura possível distinguir quem, nominal e numericamente, são as vítimas. Aquilo que se sabe é que há pessoas atingidas e que tal se dá por conta de seu pertencimento a um determinado grupo social.

A fim de manifestar-se e atingir seus objetivos danosos, o discurso de ódio deve ser veiculado por um meio comunicacional. Esse meio é escolhido de acordo com o período histórico vivido pelo autor, com suas condições aquisitivas e de acesso às tecnologias, com o público visado por este, entre outras variáveis. Inclusive, pode-se dizer que o discurso é tanto mais nocivo quanto maior o poder difusor de seu meio de veiculação. Se há alguns séculos a propagação de ideias se restringia ao círculo exíguo daqueles que sabiam ler e tinham acesso a livros, hoje essa divulgação alcança um espectro bem mais amplo de pessoas, dada à democratização educacional e à evolução dos meios comunicacionais. Tal evolução, que passa pelo rádio e pela televisão, atinge seu auge com o advento da internet. Embora as propriedades intrínsecas da rede - relativização de tempo e espaço, difusão em escala mundial, múltiplas formas de compartilhamento informacional -, propiciem rico intercâmbio entre pessoas e 
culturas, é inegável que igualmente alargam o alcance de conteúdos perniciosos, como o discurso de ódio, além de trazerem obstáculos a investigações, à ação de meios de controle ainda muito acostumados com o mundo palpável. Entre esses obstáculos tem-se a questão do anonimato, os múltiplos endereços de um mesmo sítio, a criação de perfis pessoais falsos e de comunidades com fórum fechado, ao que se somam as dificuldades em virtude do despreparo dos agentes investigadores quanto aos usos das novas tecnologias. Nesse sentido, percebe-se a necessidade de adequação, de "flexibilidade de raciocínio" (Pinheiro, 2008, p. 35) por parte dos meios de controle, principalmente do Direito.

E o Direito, tal qual construído na modernidade, tem sido constantemente desafiado pelas interações ocorridas no ambiente virtual, especialmente quando se trata de conteúdos destinados a propagar o ódio. Com efeito, muitos dos discursos proferidos com essa finalidade não encontram tipificação legal, pois no Brasil é concedido tratamento legal específico a apenas alguns tipos de discursos de ódio.

A Lei n. 7.716/89, em seu artigo 20, aponta como crime a prática de discriminação por critério de raça, cor, etnia, religião ou procedência nacional, adicionando em seu $\S 1^{\circ}$ a punibilidade de atos divulgadores do nazismo. Aos discursos de ódio embasados nesses critérios, a Lei brasileira reserva a categoria de ilicitude. Aos demais, é silente a legislação ordinária, cabendo a aplicação de medidas coadunantes com o princípio da dignidade humana (art. $1^{\circ}$, III, da Constituição Federal) - norma fundamental de plena eficácia que legitima e confere unidade de sentido à ordem constitucional brasileira (Sarlet, 2011, p. 91) -, e dispositivos a ele diretamente vinculados, como a igualdade perante a lei (art. $5^{\circ}$, caput), a igualdade de gênero (art. $5^{\circ}$, I) e a não submissão a tratamento desumano ou degradante (art. $5^{\circ}$, III). Posto que conforme o ordenamento jurídico brasileiro há discursos de ódio ilícitos e não ilícitos, neste trabalho optou-se pela adoção do termo "conteúdos prejudiciais" como gênero a englobar os últimos, em contraposição a "conteúdos ilícitos", em que estão contidos os primeiros. ${ }^{2}$ É relevante lembrar que ambos os conteúdos dizem respeito à violação de direitos fundamentais, ambos causam prejuízo, entretanto, apenas aos emissores de conteúdos ilícitos é cominada uma pena por sua conduta - grau máximo a que chega a dimensão negativa, ou defensiva, da dignidade da pessoa humana.

Feita essa breve exposição de aspectos tidos como relevantes, fica estabelecido que, ao longo deste artigo, o discurso de ódio será considerado manifestação discriminatória externalizada, que abrange os atos de discriminar e de instigar a discriminação contra determinado grupo de pessoas que possuem uma característica em comum. Seus efeitos atingem a dignidade de um grupo, não só de um indivíduo que dele faça parte. Conforme a incidência de norma legal, esse discurso pode ser configurado como ilícito. De forma ampla, tratar-se-á dele como conteúdo prejudicial, por causar prejuízo aos direitos fundamentais daqueles a quem refere. Realizada 
essa construção, imprescindível para a compreensão do tema, passar-se-á à exposição e análise de dados jurisprudenciais quantitativos.

\section{DADOS JURISPRUDENCIAIS QUANTITATIVOS E ANÁLISE}

Esta parte do trabalho tem por objetivo verificar se e em que intensidade o Poder Judiciário enfrenta demandas sobre discursos de ódio online, especificamente aqueles difundidos em redes virtuais de relacionamento, servindo-se, para isso, de duas seções. A primeira é dedicada à pormenorização do método de pesquisa utilizado na coleta de dados jurisprudenciais. A segunda apresenta os resultados quantitativos encontrados e sua análise, conforme se verá em sequência.

\section{I MÉTOdo De PeSQUisa Adotado}

A fim de obter, em um período razoavelmente curto, uma visão o mais completa possível do tratamento conferido pelo Poder Judiciário aos discursos de ódio online, realizou-se uma pesquisa jurisprudencial pela internet em tribunais recursais brasileiros que poderiam ter competência para tal demanda. Enquadraram-se nesse conceito os Tribunais de Justiça dos Estados e do Distrito Federal, os Tribunais Regionais Federais das cinco regiões, o Superior Tribunal de Justiça e o Supremo Tribunal Federal. Foram reputados como resultados da pesquisa tanto decisões monocráticas quanto acórdãos proferidos por esses juízos. Isso a fim de possibilitar uma abrangência metodológica maior e resultados mais fidedignos à posição do Poder Judiciário perante esse tipo de manifestação discriminatória.

A pesquisa jurisprudencial foi feita através dos sítios dos tribunais na internet, nos quais existem áreas que possibilitam o acesso às decisões proferidas por aquele juízo, geralmente denominadas "Jurisprudência" ou "Consulta de Jurisprudência". Os dados referidos neste artigo foram colhidos no período de 15 de agosto até 15 de setembro de 2010 .

A palavra-chave utilizada para realizar a filtragem dos resultados foi Orkut, tanto nos campos "Ementa" quanto "Inteiro teor", a fim de que a pesquisa realizada fosse limitada aos processos em que era mencionada a referida rede de relacionamentos online. Especificamente, se escolheu Orkut e não outra rede social porque 50,6\% dos seus usuários são brasileiros, segundo dados do próprio sítio (Orkut, 2010a). Isso representa 24 milhões de brasileiros interagindo (Orkut, 2010b), o que o torna uma plataforma provável para o tipo de demanda buscado. ${ }^{3}$ Também contribuiu para essa escolha o fato de as pesquisas sobre o uso das tecnologias informacionais, realizadas pelo Centro de Estudos sobre as Tecnologias da Informação e Comunicação (Cetic), órgão vinculado ao Comitê Gestor da Internet no Brasil, apontarem recorrentemente o Orkut como a principal atividade de entretenimento realizada pelos brasileiros usuários da internet (Brasil, 2010c). 
Durante a pesquisa, entendeu-se útil dividir os julgados encontrados em grandes áreas, além do discurso de ódio, para fins de comparação. A determinação dessas áreas se deu através da constatação de que algumas causas de pedir apareciam com frequência e se referiam a temas usuais na discussão sobre internet. Dividiu-se a pesquisa, portanto, nas seguintes categorias: discursos de ódio, direitos de personalidade, pornografia e outros.

Foram classificados como "discurso de ódio" os julgados cujo objeto de demanda envolvia manifestações discriminatórias dirigidas contra determinado grupo em função de uma característica partilhada por seus membros. Teve-se em conta, estritamente, discursos que configurassem dano a um grupo social e não a um indivíduo, podendo tais mensagens ser voltadas diretamente ao insulto das vítimas ou ao incitamento de práticas discriminatórias através do Orkut.

Na categoria denominada "direitos de personalidade", incluíram-se situações de violação aos direitos à honra, ao recato, à imagem e à liberdade, ou seja, os direitos de personalidade em seu aspecto moral (Amaral, 2008, p. 284). As ofensas a um indivíduo, à sua honra e liberdade foram consideradas nessa categoria, bem como o uso indevido da imagem e informações pessoais expostas na rede.

Os julgados submetidos à categoria de "pornografia" têm como característica principal a publicação ou divulgação de imagens de conteúdo sexual ${ }^{4}$ (ponto em que se distancia do direito de personalidade e à imagem).

Por fim, na categoria “outros”, que é residual, incluíram-se os resultados que não se encaixaram em nenhuma das categorias originárias, convencionadas para os fins de nosso trabalho e metodologia.

\subsection{EXPOSIÇÃO E ANÁlISE QUANTITATIVA DOS DAdOS ENCONTRADOS}

Ao fim da pesquisa jurisprudencial foi encontrado um universo total de 685 julgados correspondentes à metodologia aplicada. Destes, 595 foram resultados advindos dos Tribunais de Justiça; setenta foram os resultados obtidos nos Tribunais Regionais Federais; dezoito foi o número de decisões encontradas no Superior Tribunal de Justiça; no Supremo Tribunal Federal foram obtidos apenas dois resultados.

Do universo total de decisões correspondentes à pesquisa, "outros" foi a classificação mais encontrada (50\%), seguida por “direitos de personalidade”, que correspondeu a $45 \%$ do total de julgados encontrados. É importante ressaltar que na parcela classificada como "direitos de personalidade" pode haver litigâncias que tangenciem discursos de ódio, mas fazem-no por um viés de ofensa pessoal e são demandadas como uma violação à subjetividade da vítima, não interessando ao objetivo desse trabalho.

Os discursos de ódio representam aproximadamente 1\% (um total de 6 casos) das decisões encontradas. Isso demonstra que, mesmo em pouca quantidade, a demanda já se apresenta ao Poder Judiciário. A maioria desses processos foi de iniciativa do 
Ministério Público, instituição que tem como um de seus fundamentos a defesa de interesses sociais, representando em nome de causas que transcendem o individual, como é o caso desse tipo de discurso discriminatório.

Os números vultosos de resultados encontrados nas outras categorias, principalmente em "direitos de personalidade" e "outros", explicam-se pelo método de coleta utilizado. Nem todas as demandas encontradas se situaram necessária e exclusivamente no ambiente do Orkut. Considerou-se o bastante que o processo mencionasse a palavra "Orkut", por menos significativa que fosse sua participação no litígio. A distribuição percentual do total de julgados encontrados pode ser verificada no gráfico 1 .

\section{GRÁFICO I :}

Total de julgados encontrados (TJ, TRF, STJ, STF)

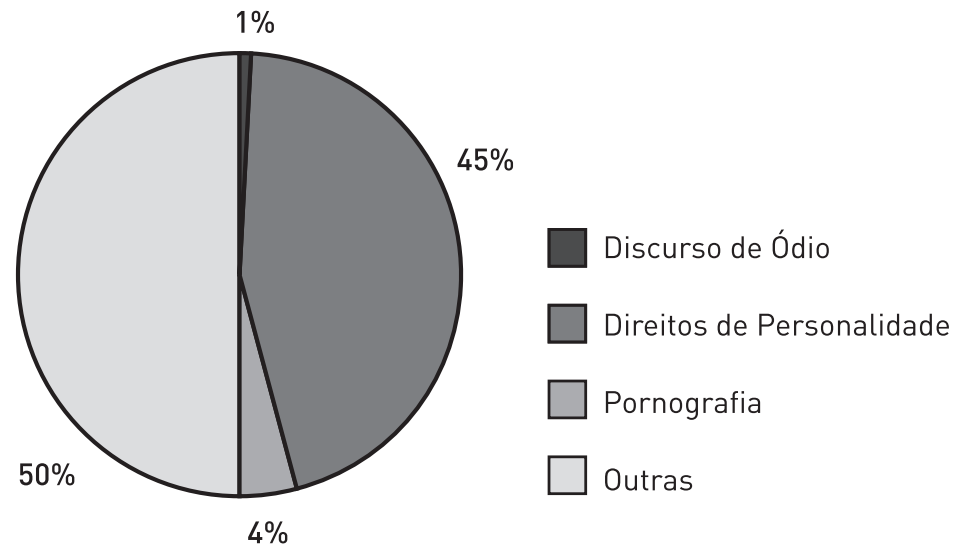

Ao efetuar-se a pesquisa nos Tribunais de Justiça (TJs), houve Estados que não apresentaram resultado algum. No Estado do Tocantins não foi possível realizar a pesquisa, pois o sítio do TJ manteve-se inacessível durante o período de coleta de dados. Em nove Estados - Alagoas, Amapá, Amazonas, Ceará, Maranhão, Pará, Paraíba, Piauí e Roraima - a pesquisa foi realizada com sucesso e descobriu-se que não havia decisões que contivessem a palavra Orkut.

É possível verificar que os Estados que não apresentaram resultados estão todos localizados nas regiões Nordeste ou Norte. Como demonstra o gráfico 2, são exatamente essas as regiões com as menores percentagens de julgados encontrados, ambas com menos de 5\%. É significativo o contraste desses resultados com os da região Sudeste, que detém a liderança no número total de julgados encontrados, com 63\% dos resultados totais, seguida pela região Sul, com 27\%. 
GRÁFICO 2:

Total de julgados encontrados em Tribunais de Justiça, por região (\%)

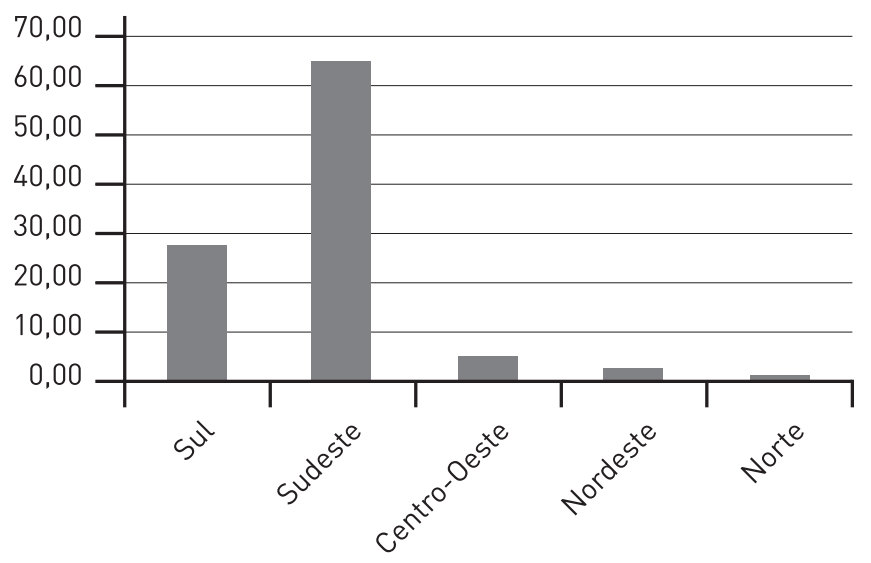

Esses dados vão ao encontro dos resultados fornecidos pelo Cetic. Na quinta edição da pesquisa sobre o uso das tecnologias da informação e comunicação no Brasil, realizada entre os meses de setembro e novembro de 2009 e divulgada no sítio do Cetic, constatou-se que a região Sudeste tem $35 \%$ dos domicílios com acesso à internet e a Sul, também com um alto índice, 32\% (Brasil, 2010c). Através desses dados, percebe-se claramente que as regiões nas quais há maior litigância são aquelas em que a população tem maior acesso às tecnologias informacionais.

Igual análise pode ser feita em relação às regiões com menos resultados (Nordeste e Norte), pois segundo a mesma pesquisa divulgada pelo Cetic, em ambas apenas $13 \%$ dos domicílios têm acesso à internet. Isso confirma a falta de acesso de algumas partes do Brasil à rede, e permite compreender a parca litigância encontrada a respeito nos tribunais. A comprovação da pouca acessibilidade ao ciberespaço nessas regiões justifica as novas normatizações e programas de inclusão digital que visam à promoção desse acesso.

Ainda trabalhando com os dados dos Tribunais de Justiça (gráfico 3), a fim de compará-los com os dos Tribunais Regionais Federais (gráfico 4), percebe-se uma diferença significativa no que concerne aos discursos de ódio. Enquanto nos TJs este tipo de discurso represente $0,34 \%$ da parcela de decisões encontradas - apenas dois em um total de 595 -, nos TRFs essa percentagem aumenta para 4,29\% - três em um total de setenta julgados encontrados. Isso se dá, mormente, em virtude de divergências sobre a competência para julgar causas relativas ao meio virtual.

O Superior Tribunal de Justiça apresentou uma decisão concernente a este assunto, o que representa $5 \%$ do total de resultados obtidos deste juízo. O Supremo Tribunal Federal, por sua vez, ficou silente quanto às manifestações discriminatórias 
publicadas em redes virtuais, apresentando apenas dois resultados encaixados na categoria "outros".

GRÁFICO 3:

Pesquisa de Julgados nos Tribunais de Justiça dos Estados

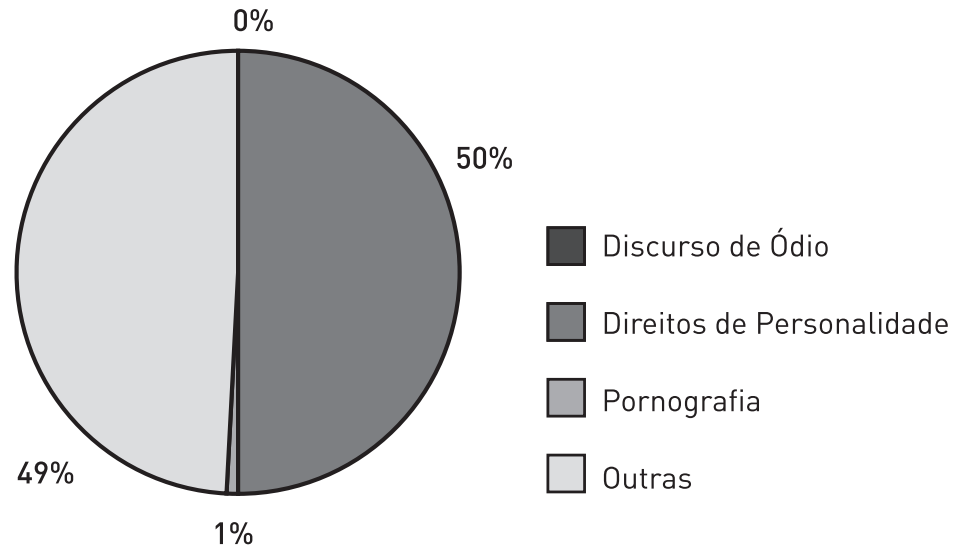

GRÁFICO 4:

Pesquisa de Julgados nos Tribunais Regionais Federais

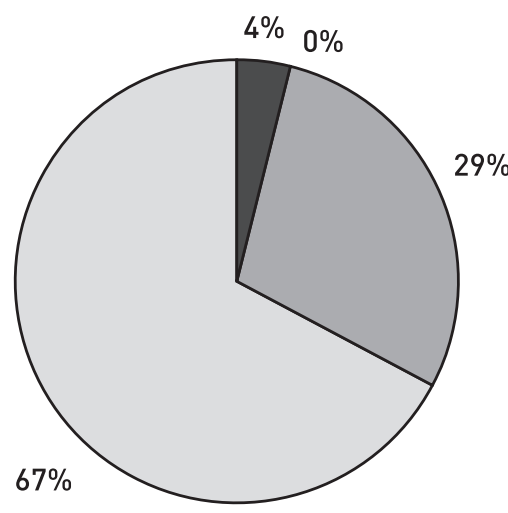

Discurso de Ódio

Direitos de Personalidade

Pornografia

A pesquisa de dados demonstrou que, de fato, o Poder Judiciário brasileiro já começa a enfrentar a matéria objeto deste artigo, os discursos de ódio presentes em 
redes como o Orkut. Sobre as razões para o escasso número de resultados é possível levantar algumas hipóteses: (a) a possibilidade de resolução dos casos em primeira instância, decisões que não foram objeto dessa pesquisa; (b) a ainda persistente noção entre os usuários de que a internet é um território não subordinado às normatizações nacionais. Pode-se também considerar que os poucos resultados se devam ao método de pesquisa, limitado a uma determinada rede social, deixando de fora uma vasta extensão de ciberespaço.

Após essas considerações, em que se verificou que o Poder Judiciário começa a enfrentar a questão do discurso de ódio online, faz-se necessário ir para o plano qualitativo da abordagem, isto é, saber como esse poder se posiciona sobre o assunto.

\section{O TRATAMENTO DA JURISPRUDÊNCIA}

Nesta seção procederemos à análise qualitativa de um julgado, com foco em uma única decisão dentre os seis resultados encontrados na pesquisa quantitativa. A jurisprudência objeto de exame, a apelação criminal 20050110767016APR, julgada pela

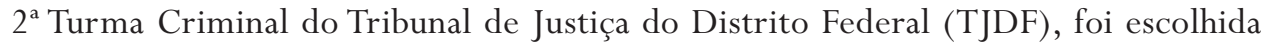
por simultaneamente atingir o mérito ${ }^{5}$ e enfrentar a materialidade do caso estudado: o discurso de ódio divulgado por rede virtual. ${ }^{6}$

Antes, porém, recordemos que a última instância da jurisdição brasileira, o Supremo Tribunal Federal (STF), já julgou no ano de 2003 um emblemático caso envolvendo discurso de ódio, conceito de raça e conflito entre princípios, no Habeas Corpus (HC) 82.424-2. Embora esse julgado não trate da disseminação de discursos de ódio na internet, nele consta o entendimento da Corte Suprema do Brasil acerca de tais conteúdos nocivos, entendimento que pode ser (e mais adiante se verá que concretamente é) utilizado como precedente quando da análise do tema no ambiente virtual.

\section{3.i Habeas Corpus 82.424-2: O entendimento do Supremo Tribunal Federal}

Como paciente do HC 82.424-2, figurou o escritor e sócio da empresa Revisão Editora Ltda., Siegfried Ellwanger, acusado do crime de racismo (art. 20 da Lei de Crimes Raciais, n. 7.716/89, com redação dada pela Lei 8.081/90) por ter sido autor de obras literárias com conteúdo antissemita, racista e discriminatório. Ele foi absolvido em primeira instância e condenado em segunda, pelo Tribunal de Justiça do Estado do Rio Grande do Sul. Por ocasião da decisão negativa em segunda instância, a defesa impetrou Habeas Corpus no Superior Tribunal de Justiça, onde, por decisão majoritária de sua $5^{\text {a }}$ Turma, o pedido foi denegado. Em 12 de setembro de 2002, sustentando a tese da prescritibilidade do crime praticado, foi impetrado novo $H C$, dessa vez no Supremo Tribunal Federal. Uma vez iniciado o julgamento, o STF decidiu pelo indeferimento da petição de $H C$ em 17 de setembro de 2003. 
De acordo com os argumentos da defesa de Siegfried Ellwanger, os judeus não constituiriam uma raça e sim um povo, fato que levaria à não incidência da conduta do paciente no crime de racismo, que, de acordo com o artigo $5^{\circ}$, inciso XLII, da Constituição Federal, é imprescritível e inafiançável. Mesmo admitindo que as manifestações do paciente possuíssem caráter discriminatório, a defesa trouxe à discussão o conceito de raça e o não enquadramento do povo judeu neste, buscando a declaração da prescrição do crime.

O HC 82.424-2 foi a fonte da qual surgiram assuntos de real importância, que necessitavam de discussão pelo Poder Judiciário. Dentre eles, a extensão do conceito de raça e a forma como se deve proceder frente a um conflito entre normas, nominadamente, entre a liberdade de expressão e a dignidade da pessoa humana.

Com relação à matéria suscitada pela defesa, o STF entendeu que o termo raça subsiste, embora não mais do ponto de vista biológico, devido à descoberta do genoma humano e à comprovação de que todos os seres humanos são biologicamente iguais. Na realidade, as raças permanecem como construções socioculturais que remetem a grupos de pessoas que partilham de uma herança cultural, religião, tradições comuns, enfim, de uma mesma identidade étnica. Daí é possível inferir que o crime de racismo, em sua acepção contemporânea, envolve "a perseguição a qualquer grupo étnico, religioso, cultural, social ou de gênero" (Meyer-Pflug, 2009, p. 204). Consoante esse viés foi o juízo do Ministro relator, Maurício Corrêa, segundo o qual, mesmo que cientificamente não se verifique a existência de divisões raciais, o racismo persiste como fenômeno decorrente de uma perspectiva histórica, política e social, sendo essa a concepção que deve ser utilizada juridicamente.

Sobre a colisão entre o direito à liberdade de expressão e o princípio da dignidade da pessoa, a maioria dos ministros do STF se posicionou a favor do entendimento de que, embora seja um "direito individual que cada cidadão possui de expressar suas ideias sejam elas quais forem, sem sofrer qualquer restrição ou ameaça por parte do Estado ou da sociedade” (Meyer-Pflug, 2009, p. 209), a liberdade de expressão não é um direito absoluto.

De acordo com o Ministro Gilmar Mendes, existem outros bens jurídicos constitucionalmente assegurados, como o pluralismo social e o respeito ao ser humano em seu valor intrínseco - a dimensão intersubjetiva da dignidade, conforme Sarlet -, que restariam sacrificados na hipótese de se dar uma amplitude irrestrita ao direito de cada cidadão de expressar o que bem entender. Assim, utilizando-se a teoria da proporcionalidade de Robert Alexy, que visa conciliar normas aparentemente divergentes, por convencimento majoritário dos ministros, decidiu-se pela limitação da liberdade de expressão em favor do princípio da dignidade da pessoa humana. ${ }^{7}$

A prevalecência desse princípio justificou-se pela dignidade humana servir de fundamento ao Estado Democrático de Direito (art. $1^{\circ}, \mathrm{III}, \mathrm{CF}$ ), figurando como o valor mais condizente com os fins almejados pela Constituição Federal, dentre os 
quais, aqueles listados no artigo $3^{\circ} .8$ Essa fundamentação do STF não implica, entretanto, que a dignidade da pessoa humana exista apenas onde e à medida que é reconhecida pelo Direito. Na realidade, o reconhecimento jurídico é relevante, não para a existência, mas para a efetiva realização e proteção da dignidade da pessoa humana (Sarlet, 2011, p. 82).

Ainda, não se quis com isso dizer que a liberdade de expressão é dispensável ou de pouca importância para a construção de uma sociedade democrática, "livre, justa e solidária" (art. $\left.3^{\circ}, \mathrm{I}, \mathrm{CF}\right)$. Não há como negar sua relevância como instrumental ao debate e à formação de opinião em uma democracia. Conforme o entendimento dominante do STF, apenas será restringido seu uso abusivo, em desrespeito à alteridade e a princípios como a igualdade e a tolerância diretamente vinculados à dignidade da pessoa humana. Tratou-se, em suma, de afirmar que o cidadão é livre para expressar suas ideias, não sendo a ele facultada, entretanto, sob esse fundamento, a prática de ilícitos ou de qualquer outra forma de violação a direitos e garantias fundamentais inscritos na Lei Maior.

A decisão de indeferimento proferida pelo Supremo Tribunal Federal no julgamento do Habeas Corpus 82.424-2 trouxe à luz o tratamento constitucionalmente adequado a ser conferido a discursos de intolerância. É possível dizer que a prolatação dessa sentença e as percepções dela advindas, embora haja entendimentos divergentes, significam certa segurança jurídica e um importante precedente a ser utilizado pelos magistrados das demais instâncias, quando do surgimento de novos casos relativos a discursos de ódio. Resta saber se e como tal interpretação se estenderá aos discursos veiculados pelo meio virtual.

\subsection{O entendimento do Tribunal de Justiça do Distrito Federal}

Após a exposição de como o Supremo Tribunal Federal, corte que orienta as decisões proferidas pelo Poder Judiciário, percebe a questão do discurso de ódio, partir-se-á para a análise do caso que, em nossa pesquisa, considerou-se emblemático no que concerne ao tratamento judicial conferido ao este tipo de discurso propagado no ciberespaço. Trata-se da apelação 20050110767016APR, julgada pela $2^{\text {a }}$ Turma Criminal do Tribunal de Justiça do Distrito Federal em 2011.

Em setembro de 2009, o TJDF decidiu recurso interposto pelo Ministério Público (MP) contra sentença que absolveu Marcelo Valle Silveira Mello do crime de racismo. Segundo o relatório, o réu, ao fazer críticas ao sistema de cotas adotado pela Universidade de Brasília, teria publicado no Orkut textos com conteúdo explicitamente ofensivo a pessoas negras, referindo-se a elas como "burros, macacos subdesenvolvidos, ladrões, vagabundos, pobres”, entre outras denominações pejorativas. A sentença de primeira instância julgou improcedente a pretensão punitiva do Estado, absolvendo o réu e alegando não constituir infração penal o fato a ele imputado (art. 386, III, do Código de Processo Penal). Frente a essa decisão, o 
MP prontamente interpôs um recurso de apelação, arguindo que a conduta de Marcelo caracterizaria o crime de discriminação da raça negra através de meios de comunicação social, com fulcro no artigo 20, $\S 2^{\circ}$, da Lei n. 7.716/89.

Em sua fundamentação, o MP ressaltou que a juíza de primeira instância desviou sua atenção da conduta racista do apelado para sua personalidade, atendo-se ao fato de este ter ficado órfão de pai em tenra idade, haver sido criado por mãe mentalmente desequilibrada e ser portador de distúrbio mental. Munido de laudo de exame psiquiátrico, o MP apontou que todas essas contingências não comprometeriam a capacidade de entendimento de Marcelo Mello, apenas sua capacidade de determinação, sendo caso de semi-imputabilidade e, portanto, de penalização, ainda que de tempo reduzido (art. 26, parágrafo único, do Código Penal). Afirmou, ainda, que o apelado tinha plena consciência do que fazia e, dado o uso reiterado de adjetivos negativos, teria agido com dolo direto de discriminar a coletividade negra.

Em resposta, a defesa de Marcelo Mello alegou a atipicidade da conduta, pela não demonstração do elemento subjetivo, o dolo. Assinalou o teor puramente crítico das manifestações publicadas no Orkut acerca do sistema de cotas. Ademais, assegurou que as menções ao critério racial fulcraram-se em mero animus jocandi, tendo-se tornado mais agressivas por ter o apelado de defender-se de provocações ulteriores provindas de outros internautas.

Ponderadas essas circunstâncias e argumentações, o juiz relator do acórdão, o Desembargador Roberval Casemiro Belinati, decidiu por dar razão ao MP, enquadrando a conduta de Marcelo Mello no crime de racismo. Essa decisão baseou-se essencialmente na análise das colocações virtuais do réu que, embora tivessem como objetivo inicial criticar o sistema de cotas universitárias, ao ver do juiz, foram desvirtuadas em manifestações livres e conscientes de preconceito contra o negro e sua cultura. A sentença compartilhou o juízo do STF de que o direito à liberdade de expressão não abrange a prática de ilícitos ou de outras formas de violação à dignidade da pessoa humana. De maneira a elucidar tal entendimento, faz-se útil a reprodução e comentário de alguns trechos do discurso online de Marcelo contidos no processo. No contexto da política de cotas, o apelado repetidamente tratou o negro como inferior ao branco, do ponto de vista intelectual:

... infelizmente em universidade pública não dá camarada, pra branco passar precisa tirar 200, e pros macacos passarem eh soh tirar - [menos] 200 (...) esses pretos vão eh estragar a universidade pública mais do que já estragaram... não sabem nem escrever... (...) agora vem com esse negócio de cotas.. quer dizer que agora vcs querem justificar a cor pra culpar a gente do fracasso de vcs.

Fez o mesmo comparativo, pelo viés cultural: 
Os caras [os adeptos do nazismo] pelo menos pagam pau pros europeus que são uma das nações mais desenvolvidas do mundo e Adolf Hitler, que sem dúvida foi um grande homem pra história e pro seu país pq queiram ou não, o cara tirou a Alemanha da miséria. E vcs [negros], ficam aí pagando pau da África, aquele bando de macacos subdesenvolvidos, querendo atribuir valor a essa "cultura” negra que só tem músicas sem sentido e toscas que não fazem mais que promover orgias sexuais.

E logo passou a agressões gratuitas, sem qualquer conexão com o assunto das cotas universitárias, referindo-se ao negro como criminoso e passivo de outras analogias degradantes:

... até me dá vontade de virar um skin-head também (...) só acho que eles [skin-heads] tão perdendo tempo pq vcs macacos vão acabar na prisão mesmo (...) preto no céu é urubu, preto correndo é ladrão, preto parado é bosta. Qual a diferença entre o preto e o câncer (?) R: o câncer evolui! (...) vou jogar a real pra vcs, seus macacos burros (...) vão estudar sua cambada de vagabundo (...) já não basta preto roubando dinheiro (...) agora ele também rouba vaga nas universidades (...) o que mais vai roubar depois?

O teor grosseiro dessas colocações demonstra a dupla face do discurso de ódio: o insulto e a incitação. No que tange ao insulto, está claro que Marcelo Mello despiu completamente a coletividade negra de sua dignidade, começando pela maneira como se refere a eles: "macacos". Não reconheceu o negro como sujeito igual a ele. Subestimou sua capacidade intelectual, tratando-o como analfabeto ou, no mínimo, intelectualmente menos capaz que o branco. Desrespeitou a cultura negra, referindo-se a ela como algo puramente animalesco, de menor valor, se comparada à europeia. Desses elementos tem-se a discriminação.

Do ponto de vista da incitação, percebe-se que Marcelo Mello utilizou certa lógica persuasiva (deturpada, mas ainda assim, lógica) em suas estruturas discursivas. Baseando-se no tema das cotas em universidades públicas, Marcelo construiu uma situação de antagonismo entre o negro, considerado "ladrão de vagas universitárias", ingressante sem qualquer mérito ou capacidade, e o branco, vítima das novas medidas de ingresso, que deve sempre contar com seus próprios e esmerados esforços para atingir o ensino superior.

Essa forma de raciocínio é propícia para a angariação de seguidores, pois a imagem de um opositor claro facilita a identificação das pessoas com uma causa ou movimento (Brown, 1971, p. 81ss.). Ademais, a fim de fomentar sua tese, Marcelo fez uso de estereótipos ("músicas toscas e sem sentido"), substituiu nomes de forma 
pejorativa ("macacos subdesenvolvidos, pretos") e repete diversas vezes as mesmas premissas (a analogia entre negros e criminosos, p.ex.). A esses fatores somam-se os recorrentes apelos emocionais em seu discurso, apelos sem qualquer justificativa lógica para a temática das cotas universitárias (“preto no céu é urubu”), mas relevantes no sentido de despertar simpatia. Todos esses elementos, destacados da fala de Marcelo Mello, contribuem para infirmar a tese de sua defesa, pois a racionalidade lógica utilizada pelo internauta, apesar de ser discriminatória e, por conseguinte, reprovável, demonstra que o autor das ofensas detinha capacidade argumentativa, valendo-se dos recursos linguísticos necessários para que seu discurso angariasse simpatia e seguidores.

Em sua conclusão pela incidência da conduta do apelado no crime previsto pelo artigo 20, $\S 2^{\circ}$, da Lei 7.716/89, tendo analisado o fato, a publicação por Marcelo Mello de comentários inferiorizadores da raça negra através da internet, e o elemento subjetivo, indicado como dolo, dada a estruturação lógica e intencional das manifestações, o juiz relator apoiou-se, por fim, no precedente do STF relativo a discursos de ódio, o HC 82.424-2. Segundo o Desembargador Roberval Casemiro Belinati, o discurso discriminatório de Marcelo não está protegido pela liberdade de expressão (art. $5^{\circ}, \mathrm{IV}, \mathrm{CF}$ ), pois tal direito deve ser exercido de forma harmônica, não abrigando a prática de condutas criminosas. Excessos ao direito de livre manifestação do pensamento serão passíveis de responsabilização civil e penal, posto que a Constituição Federal apresenta expressa vedação ao racismo (art. 5 , XLII, CF) e tem como fundamento a dignidade da pessoa humana (art. $1^{\circ}$, III, CF). Subjaz a esse entendimento, ademais do valor de cada pessoa por sua qualidade intrínseca de ser humano - dimensão ontológica da dignidade -, o dever geral de respeito exigido por conta desse atributo - dimensão intersubjetiva da dignidade -, não sendo toleradas quaisquer ações que, sob o estandarte da liberdade de expressão, impliquem a desvalorização de determinado grupo social.

\subsection{BreVES NOTAS COMPARATIVAS ENTRE OS DOIS JULGADOS}

Feita a exposição dos julgados, o HC 82.424-2 e o recurso ao TJDF, e a partir da análise das sentenças prolatadas pelo Poder Judiciário, faz-se possível traçar um comparativo entre as circunstâncias de cada caso e as peculiaridades das decisões.

Com relação ao HC 82.424-2, julgado pelo STF, a decisão deu-se a favor da restrição à liberdade de expressão, caracterizando a conduta do agente como discurso de ódio. Devido à pluralidade de opiniões sobre o assunto, o posicionamento emitido pelo STF deu ensejo a fortes discussões sobre o alcance da liberdade de expressão, a abrangência do conceito de raça e a fidelidade ao princípio da dignidade da pessoa humana.

O fator que instigou a existência de várias opiniões referentes a esse julgamento foi o fato de Siegfried Ellwanger ter usado livros como meio de expor suas ideias. De acordo com Michel Rosenfeld, o impacto gerado pelo discurso de ódio depende 
essencialmente do meio de comunicação utilizado (Rosenfeld, 2001, p. 50). Por esse viés, sendo o livro um meio que permite ao leitor optar conhecer ou não um assunto, é passível de aceitação (ou, no mínimo, ponderação) o entendimento de que os conteúdos apresentados pelo escritor se enquadrariam como livre expressão do pensamento. ${ }^{9}$ Entretanto, conforme já foi referido, o STF optou por juízo diverso, conforme as decisões das cortes constitucionais de países europeus e do Tribunal Europeu de Direitos Humanos, inclinando-se a considerar que o problema reside não no meio utilizado, mas sim na divulgação em si de conteúdo com o escopo de atingir determinado grupo social.

Essa possibilidade alternativa de raciocínio encontra uma dificuldade consideravelmente maior de manter-se no caso do recurso julgado pelo TJDF. As mensagens veiculadas por Marcelo Mello são insultos explícitos, não se cobrem da linguagem própria dos livros. Por ferir a dignidade do grupo-alvo de forma crua e grosseira, o abuso à liberdade de expressão é imediatamente reconhecível. Ademais, as manifestações do réu se propagaram através do espaço virtual, na rede social de relacionamento Orkut. Essa circunstância, conforme o raciocínio de Rosenfeld, torna tanto mais gravosa a conduta do agente, pois o meio utilizado, a internet, propicia o acesso de um largo escopo de pessoas às mensagens, muitas vezes sem que elas possam decidir se desejam ou não tomar conhecimento de seus conteúdos. Tais contingências tornam o caso de Marcelo Mello uma extrapolação escancarada à liberdade de expressão, dando ínfima margem para deliberação em contrário.

Apresentados os casos concretos e feitas as considerações, pode-se inferir que o Poder Judiciário Brasileiro vem tratando os discursos de intolerância, manifestos ou não no ambiente virtual, de maneira repressiva. As decisões tomadas deram-se pela limitação do alcance da liberdade de expressão em favor da dignidade da pessoa humana, demonstrando a dimensão negativa, defensiva, desse atributo. Tal prevalência se deu pelo caráter fundamental da dignidade, por esta traduzir-se em um princípio que, segundo Giorgi, "ilumina todos os outros princípios e normas do nosso ordenamento" (2007, p. 262).

\section{CONSIDERAÇÕES FINAIS}

Este artigo se propôs a verificar se e como o Poder Judiciário brasileiro trata as demandas sobre discurso de ódio exposto em redes sociais do meio virtual. Ao longo da pesquisa, foi construída uma conceituação satisfatória para este tipo de discurso, houve a obtenção de dados quantitativos relativos a processos nos tribunais e foram alcançados resultados passíveis de uma análise aprofundada. Entretanto, longe de essas etapas mostrarem respostas inquestionáveis e definitivas, na realidade, ensejaram mais perguntas, mais pontos a serem explorados sobre discurso de ódio, sociedade e Direito. 
De fato, a pesquisa quantitativa realizada revelou que o Poder Judiciário recebe processos relativos a discurso de ódio online. No entanto, os números são ínfimos se comparados com os de outras espécies de demanda ou com a incidência de denúncias a esse tipo de conduta. Qual é a causa dessa discrepância? Resolução das causas em primeira instância ou através de meios extraprocessuais? Persistência da percepção, derivada do senso comum, de que a internet está fora dos limites da lei, adiantando muito pouco recorrer ao Poder Judiciário? Consideração de que a violência e a depreciação a grupos sociais são, contemporaneamente, atos banais, "naturais"?

Os julgados analisados revelaram o caráter não absoluto da liberdade de expressão, direito que não pode servir de suporte para o cometimento de violações, a fim de que se resguarde o princípio da dignidade da pessoa humana. Em ambos os casos, houve incidência da Lei n. 7.716/89, que confere caráter de ilicitude aos discursos de ódio embasados nos critérios arrolados no artigo 20, quais sejam, raça, cor, etnia, religião e procedência nacional. Restam algumas questões. Qual é o procedimento a ser adotado para situações em que se consumar discriminação por outro critério? Como se trata o discurso odiento de gênero? E a idosos? E aquele proferido contra homossexuais? Visto que não há lei ordinária regulamentando a matéria, são aplicados diretamente os dispositivos constitucionais? Ademais, aquilo que faticamente se percebeu e analisou foi o tratamento conferido aos emissores do discurso de ódio, não ao discurso em si, e tampouco se identificou qualquer preocupação com a vítima, quer na sua forma individual, quer se adote o conceito de vitimização difusa.

Por certo que da maneira como foram tratados os agentes se depreende o posicionamento repressivo do Poder Judiciário, quanto a esse tipo de manifestação. Entretanto, o que é efetivamente feito do discurso? O livro de Siegfried Ellwanger continua em circulação? As páginas virtuais em que Marcelo Mello se exaltou permanecem no ar? A supressão desses conteúdos é viável? Essas são algumas das interrogações que restam sem resposta.

É notável o quanto se falou ao longo deste trabalho sobre dignidade da pessoa humana. Contudo, essencialmente em sua dimensão negativa, com vistas à restrição de outros direitos cujo abuso poderia colocá-la a perigo. Faz-se necessário lembrar que a proteção a esse princípio também possui sua dimensão positiva, promotora de direitos, que é de igual valia (senão maior) para o combate ao discurso de ódio. Dado que o preconceito nasce da ignorância, para enfrentá-lo deve-se usar da troca de conhecimentos, do diálogo entre culturas. O branco necessita conhecer a cultura do negro. O árabe deve tentar compreender os costumes do judeu. Em sua diversidade, o homem precisa entender que não há hierarquias. Cada indivíduo, em suas peculiaridades, em sua pertença a determinado grupo, possui tanto valor quanto outro indivíduo oriundo de diferentes contingências. Daí surge a necessidade de adoção de políticas pluralistas, promotoras da interculturalidade, podendo-se para tal aproveitar inclusive o grande potencial difusor das mídias cibernéticas. Deve-se ter em mente 
que a mera sanção ao emissor do discurso discriminatório não muda suas ideias, não o impede de voltar a propagá-las. Aquilo que de fato torna um ambiente, real ou virtual, mais digno e saudável é o reconhecimento social de que o outro, a alteridade, tem valor e deve, portanto, ser respeitado.

: ARTIGO APROVADO (08/12/2011): RECEBIDO EM 11/07/2011

\section{NOTAS}

1 Essa paráfrase remete ao seguinte trecho: "in the opinion of one group in the community, members of another group are not worthy of equal citizenship" (Waldron, 2010, p. 1601).

2 Essa classificação em espécies de conteúdo advém da proposta de decisão do Parlamento Europeu e do Conselho 2008/0047 (COD), que estabelece um programa comunitário plurianual para a proteção das crianças que utilizam a internet e outras tecnologias das comunicações. Sua Exposição de Motivos explica a distinção entre os conteúdos ilícito e prejudicial: "Aquilo que se considera ilícito varia de país para país, sendo definido pela legislação nacional aplicável e sendo objecto da acção [sic] das forças policiais e judiciais e de outros organismos públicos. (...) Conteúdos prejudiciais são conteúdos que pais, professores e outros adultos consideram serem [sic] prejudiciais para as crianças. A sua definição varia com os países e as culturas, podendo ir da pornografia e da violência ao racismo, à xenofobia, ao ódio no discurso e na música e a sítios que fomentam a automutilação, a anorexia e o suicídio. (...) Os Estados-membros diferem no grau de sensibilidade (...) e na gravidade atribuída à exposição das crianças a conteúdos potencialmente prejudiciais. (...) Existem vários meios para lidar com os conteúdos prejudiciais (...) são exemplos o controlo [sic] da efectiva aplicação das disposições jurídicas, a autorregulação, as ferramentas de controlo [sic] parental e as acções [sic] de sensibilização e educação." (União Europeia, 2010, p. 4).

3 De acordo com dados da organização não governamental SaferNet Brasil, comparando-se o mês de junho de 2006 com seu correspondente em 2010, o número de denúncias acerca de discursos de ódio em redes virtuais de relacionamento, como o Orkut, aumentou quase 92\%. Essa porcentagem foi inferida de tabelas de denúncias realizadas no próprio site da ONG (Safernet, 2010).

4 Na categoria "pornografia" estão incluídas, além da publicação e divulgação de imagens pornográficas de pessoas maiores de 18 anos, também situações de pedofilia.

5 Dos seis julgados sobre discursos de ódio online encontrados em nossa pesquisa, quatro não analisaram o mérito, atendo-se a meras pendências processuais. Essas discussões de caráter processual abordaram, sobretudo, conflitos de competência para julgamento das causas. É possível explicar a recorrência desses conflitos pela peculiar característica espacial da rede, sua desterritorialização. Para o Direito, acostumado com noções fixas e delimitadas de espaço, surge uma inesperada dificuldade de se identificar o local de consumação de condutas ensejadoras do litígio, critério imprescindível para o julgamento da lide. De acordo com o art. 109, inciso V, da Constituição Federal, se o ato danoso realizou-se no exterior (internacionalidade da conduta), incide a competência da Justiça Federal. Já se a conduta se manteve nos limites nacionais, compete à Justiça Estadual julgá-la. Entretanto essas delimitações se tornam fluídas no ambiente virtual. Até que ponto se pode dizer que uma informação se propagou em âmbito nacional se a internet é uma rede de acesso em escala mundial? Ademais desse ponto, encontrou-se nos referidos resultados discussões de competência envolvendo os institutos da conexão e prevenção. 
6 Dentre os julgados classificados como decisões que atingiram o mérito, o HC 990.09.328412-0, apreciado pelo Tribunal de Justiça do Estado de São Paulo, não será analisado, por apresentar pouca relevância para este trabalho. Mesmo sendo efetuada a análise do pedido pelo magistrado, não há deliberações diretas acerca do tratamento a ser conferido a discursos incitadores de práticas discriminatórias. O juiz limita-se a realizar subsunções normativas com vistas à concessão ou não do instituto de Habeas Corpus.

7 De encontro à posição adotada pela maioria dos membros da Suprema Corte brasileira, os ministros vencidos entenderam que restrições à liberdade de expressão apenas são possíveis em casos especialíssimos, em que a opinião manifestada seja excessivamente discriminatória, fisicamente contundente ou capaz de expor pessoas a situação de risco iminente, e em tais situações não se enquadraria o caso analisado. Para o Ministro Marco Aurélio de Mello, a liberdade de expressão é um dos pilares da democracia, e como tal, qualquer forma de proibição a ela pode ser equiparada à censura, nociva ao próprio cerne do Estado democrático. Interessante também sua posição quanto à criminalização de práticas discriminatórias e sua correspondência a valores sociais, quando diz que "como o Brasil não possui uma história de antissemitismo, não há sentido em criminalizar a conduta do paciente” (Brasil, 2011 , p. 857 ss.).

8 "Art. $3^{\circ}$. Constituem objetivos fundamentais da República Federativa do Brasil: I - construir uma sociedade livre, justa e solidária; II - garantir o desenvolvimento nacional; III - erradicar a pobreza e a marginalização e reduzir as desigualdades sociais e regionais; IV - promover o bem de todos, sem preconceitos de origem, raça, sexo, cor, idade e quaisquer outras formas de discriminação” (Brasil, 2010a).

9 Esse entendimento é encontrado em Meyer-Pflug (2009, p. 208): “O livro não é algo imposto ao cidadão, é necessária uma predisposição para a leitura de uma obra, diferentemente do que ocorre no caso da distribuição de panfletos. No caso dos panfletos tem-se que a finalidade única de sua distribuição é a de fomentar o racismo e suas práticas, ou seja, o objetivo daquela manifestação não é outro senão a de gerar uma ação concreta ilegal”.

\section{REFERÊNCIAS BIBLIOGRÁFICAS}

AMARAL, Francisco. Direito Civil: introdução. 7. ed. rev. e atual. Rio de Janeiro: Renovar, 2008.

BRASIL. Constituição (1988). Constituição da República Federativa do Brasil: promulgada em 5 out. 1998. Disponível em: www.planalto.gov.br/ccivil_03/constituicao/constitui\%C3\%A7ao.htm. Acesso em: 10 out. 2010a.

. Lei n. 7.716, de 5 jan. 1989. Define os crimes resultantes de preconceito de raça ou de cor. Disponível em: www.planalto.gov.br/ccivil/Leis/L7716.htm. Acesso em: 12 nov. 2010b.

. Pesquisa sobre o uso das Tecnologias da Informação e da Comunicação no Brasil: TIC Domicílios e Usuários 2009 - Área Urbana. São Paulo: Comitê Gestor da Internet no Brasil, 2010. Disponível em: www.cetic.br/usuarios/tic/2009/index.htm. Acesso em: 13 nov. 2010c.

. Supremo Tribunal Federal. Habeas corpus. Publicação de livros: antissemitismo. Racismo. Crime imprescritível. Conceituação. Abrangência constitucional. Liberdade de expressão. Limites. Ordem denegada. Habeas corpus 82.424-2. Relator: Min. Moreira Alves. Data do julgamento: 17/09/2003. DJ 19/03/2004. Disponível em: http://redir.stf.jus.br/paginadorpub/paginador.jsp?docTP=AC\&docID= 79052. Acesso em: 18 nov. 2011.

BROWN, J. A. C. Técnicas de Persuasão - Da propaganda à lavagem cerebral. 2. ed. Rio de Janeiro: Zahar Editores, 1971.

BRUGGER, Winfried. Proibição ou proteção do discurso do ódio? Algumas observações sobre o direito alemão e o americano. Revista de Direito Público, v. 15 n. 117, jan./mar. 2007.

DISTRITO FEDERAL. Tribunal de Justiça do Distrito Federal e dos Territórios. $2^{\text {a }}$ Turma Criminal. Apelação criminal interposta pelo Ministério Público contra sentença que absolveu o réu do crime de racismo praticado no "Orkut", site de relacionamentos da internet, art. 20, §2², Lei 7.716/1989. Autoria, materialidade, adequação típica e elemento subjetivo comprovados. Sentença reformada. Condenação imposta. Réu semi-imputável. Continuidade delitiva. Pena privativa de liberdade substituída por restritivas de direito. Recurso conhecido e parcialmente provido. Apelação N. 20050110767016APR. Relator: Roberval Casemiro Belinati. Data do julgamento: 03/09/2009. DJ 17/11/2009. Disponível 
em: http: / / tjdf19.tjdft.jus.br/cgi-bin/tjcgi1?DOCNUM=2\&PGATU=1\&l=20\&ID=62413,77380, 18668\&MGWLPN=SERVIDOR $1 \& N X T P G M=$ jrhtm03\&OPT $=\& O R I G E M=I N T E R$. Acesso em: 18 nov. 2011.

GIORGI, Tânia Giandoni Wolkoff. Princípios constitucionais e o princípio da dignidade humana. Revista de Direito Constitucional e Internacional, ano 15, n. 59, abr./jun. 2007.

MEYER-PFLUG, Samantha Ribeiro. Liberdade de Expressão e Discurso de Ódio. São Paulo: Ed. Revista dos Tribunais, 2009.

ORKUT. Dados Demográficos. Disponível em: www.orkut.com.br/Main\#MembersAll.aspx. Acesso em: 11 out. 2010a.

. Alcance o seu público-alvo em um dos sites mais visitados do Brasil... Disponível em:

www.orkut.com/html/advertise/BR/overview.html. Acesso em: 13 nov. 2010b.

PINHEIRO, Patricia Peck. Direito Digital. 3. ed. São Paulo: Saraiva, 2009.

ROSENVELD, Michel. Hate speech in constitutional law jurisprudence: a comparative analysis. Working Papers Series 41, 2001.

SAFERNET. Indicadores. Disponível em: www.safernet.org.br/site/indicadores. Acesso em: 12 out. 2010. SARLET, Ingo Wolfgang. Dignidade da pessoa humana e direitos fundamentais na Constituição Federal de 1988. 9. ed. rev. e atual. Porto Alegre: Livraria do Advogado, 2011.

SEVERINO, Antônio Joaquim. Metodologia do trabalho científico. 23. ed. rev. e atual. São Paulo: Cortez, 2007. UNIÃO EUROPEIA. Comissão das Comunidades Europeias. Proposta de decisão do Parlamento Europeu e do Conselho, 27 fev. 2008, que estabelece um programa comunitário plurianual para a protecção das crianças que utilizam a internet e outras tecnologias das comunicações. Disponível em: http:/ / eurlex.europa.eu/LexUriServ/LexUriServ.do?uri=COM:2008:0106:FIN:PT:PDF. Acesso em: 12 nov. 2010 .

WALDRON, Jeremy. Dignity and Defamation: the Visibility of Hate. Harvard Law Review, v.123, n.1596 (2010), p. 1597-1657.

Rosane Leal da Silva

Rua Marechal Floriano Peixoto, n. 1184, sala 105 Núcleo de Direito Informacional (UFSM) - 97015-372 Santa Maria - RS - Brasil rolealdasilvalagmail.com

Rua Marechal Floriano Peixoto, n. 1184, sala 105 Núcleo de Direito Informacional (UFSM) - 97015-372 Santa Maria - RS - Brasil dessanichelagmail.com

Rua Marechal Floriano Peixoto, n. 1184, sala 105 Núcleo de Direito Informacional (UFSM) - 97015-372 Santa Maria - RS - Brasil laclaramartinslagmail.com
Professora adjunta do Curso de Graduação em Direito da UNIVERSIDADE FEDERAL DE SANTA MARIA (UFSM) CoORdenadora do Núcleo de DiReito INFORMacional (NUDI), UFSM

\section{Andressa Nichel}

ACAdÊMICA dO $5^{\circ}$ SEMESTRE dO CuRSO dE GRAduAÇÃo EM DiREITo dA Universidade FEDERAL de SANTA MARIA (ÜFSM) INTEGRANTE DO NúClEO DE DiREITO INFORMACIONAL (NUDI), UFSM

\section{Anna Clara Lehmann Martins}

ACADÊMICA dO $5^{\circ}$ SEMESTRE do CuRSO dE GRAduAÇÃo EM Direito da Universidade Federal de SANTA Maria (UFSM)

INTEGRANTE DO NúClEO DE DIREITO INFORMACIONAL (NUDI), UFSM 


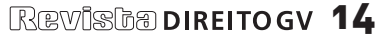

Rua Marechal Floriano Peixoto, n. 1184, sala 105 Núcleo de Direito Informacional (UFSM) - 97015-372 Santa Maria - RS - Brasil carlise_kblahotmail.com
ROSANE LEAL DA SILVA E OUTROS: $\mathbf{4 6 7}$

Carlise Kolbe Borchardt

Acadêmica do $5^{\circ}$ Semestre do Curso de Graduação em Direito da Universidade Federal de SANTA Maria (UFSM) INTEGRANTE DO NúCLEO DE DIREITO INFORMACIONAL (NUDI), UFSM 
